\title{
HABITUS PROFISSIONAL, CURRÍCULO OCULTO E CULTURA DOCENTE: PERSPECTIVAS PARA A ANÁLISE DA PRÁTICA PEDAGÓGICA DOS PROFESSORES DE EDUCAÇÃO FÍSICA
}

\author{
Mônica URroz Sanchotene* \\ Vicente Molina Neto**
}

\section{RESUMO}

O presente ensaio pretende articular conceitos de habitus profissional, currículo oculto e cultura docente, como instrumentos de análise das práticas pedagógicas dos professores de educação física. Ao conceber a prática pedagógica como resultado de um contexto e de um habitus profissional, o texto discute a produção de um currículo oculto a partir da prática docente, considerando que o currículo oculto pode ser fruto das relações interpessoais, das normas escolares e dos conteúdos de uma disciplina/componente curricular. O ensaio mostra, ainda, como o fenômeno da intensificação reforça as rotinas dos professores e dificulta a reflexão a partir da prática.

PALAVRAS-CHAVE: prática pedagógica - habitus profissional - currículo oculto

\section{INTRODUÇÃO}

presente artigo visa discutir a prática pedagógica dos professores
de educação física, compreendendo-a como fruto de um contexto e de um habitus profissional, responsável pela produção do currículo oculto na escola. Nos propusemos a relacionar o habitus profissional com os saberes utilizados pelos professores e com o currículo oculto, analisando seus limites e possibilidades na perspectiva de transformação das práticas pedagógicas.

A análise destes conceitos se identifica com a teoria crítica enquanto fundamentação teórica, centrando a análise no sistema de ensino como uma das instituições responsável pela reprodução das relações sociais

* Integrante do Grupo de Estudos Qualitativos Formação de Professores e Prática Pedagógica em Educação Física e Ciências do Esporte e estudante de mestrado do Programa de Pós-graduação em Ciências do Movimento Humano/EsEF/ UFRGS.

** Professor da graduação e da pós-graduação da EsEF-UFRGS. 
desiguais da sociedade capitalista. Não se descartam, porém, os conflitos e as possibilidades de resistência que coexistem nessas instituições.

\section{REVISANDO OS CONCEITOS}

A escola tem sido freqüente objeto de estudo e as preocupações em torno dela são muito variáveis. Por muito tempo, as análises destacavam os índices de entrada e de saída da escola, depois deram destaque à aprendizagem dos alunos e, posteriormente, visavam descortinar o papel do professor e do currículo escolar, entre outros aspectos.

O tema central deste artigo é o debate que se estabelece em torno dos fatores constituintes e intervenientes da prática pedagógica dos professores. Para tanto, utilizamos as análises de Perrenoud et al (2001) sobre o habitus profissional; de Silva (1992), Apple (1994, 1989), Perrenoud (1996) e Torres Santomé (1994) a respeito do currículo oculto; e, de Silva (1992), Molina Neto (1997) e Tardif (1991) em relação ao conceito de cultura docente.

Interessam-nos as aprendizagens dos alunos, resultantes das relações interpessoais que se desenvolvem na escola e/ou aquelas aprendizagens que não constam nos planejamentos escolares e que consideramos fruto do habitus profissional dos professores, ou seja, procuramos entender como se produz um currículo oculto por meio das práticas pedagógicas, em grande medida, estruturadas a partir do habitus profissional dos professores.

O esquema a seguir tornará mais clara a perspectiva de análise:

Habitus Profissional

Contexto Escolar (situação)

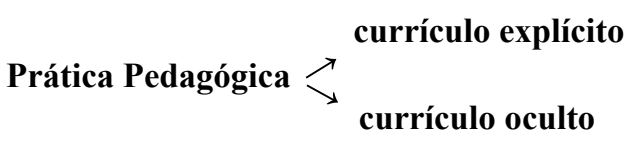

Além disso, pretendemos compreender como estas relações intervêm nas possibilidades de mudança das práticas pedagógicas e de que forma relacionam-se com as condições de trabalho dos professores, cada vez mais intensificadas e colonizadas (HARGREAVES, 1996).

A análise da escolarização baseada no habitus profissional e no currículo oculto subentende um marco teórico aliado à teoria crítica. Ao propor uma análise da prática pedagógica amparada pela teoria crítica torna-se importante esclarecer que, nesta concepção, compreende-se a escola como um local de socialização, que adapta os indivíduos a uma 
sociedade desigual e excludente, e, dessa forma, conforma-os. A escola é local de transmissão e de reprodução da cultura dominante.

Para Bourdieu (2002, p. 14), "o sistema de ensino é um dos mecanismos pelos quais as estruturas sociais são perpetuadas”. É importante ressaltar que o sistema de ensino contribui para conservar as estruturas, e que existem outros sistemas que também cumprem esta função, como por exemplo, o sistema econômico.

Nesse sentido, citamos Bowles e Gintis (1981), que consideram a escola um local de reprodução das relações sociais da sociedade capitalista. A análise dos autores baseia-se na correspondência das relações no interior da escola com as relações sociais desiguais. A correspondência se processa, fundamentalmente, por meio da hierarquia escolar e pelo tipo de estrutura de relação que se desenvolve no interior da escola. Há uma relação de subordinação entre a direção e os professores e entre os professores e os alunos que os prepara para as relações de trabalho na sociedade capitalista, que os adapta.

Nos afastamos desta visão determinista e concordamos com Apple (1989) quando o autor afirma não considerar que a reprodução social por meio da escola aconteça por um processo mecânico. Segundo o autor, a escola, com base nos currículos explícito e oculto, produz nos alunos alguns saberes, valores e comportamentos que os preparam para o trabalho na sociedade capitalista. Para Apple, no entanto, esta relação não é mecânica e não está isenta de contradições. As análises do sistema de ensino devem buscar os pontos de contradição e as resistências. Sendo assim, neste trabalho, a noção de reprodução é compreendida de forma não-mecânica, como atribuição do sistema de ensino, mas não isenta de conflitos.

Com o intuito de superar a visão mecânica e determinista da reprodução social, Bourdieu (1983, p. 64) sugere que "é preciso abandonar todas as teorias que tomam explícita ou implicitamente a prática como uma reação mecânica, diretamente determinada pelas condições antecedentes e inteiramente redutível ao funcionamento mecânico de esquemas preestabelecidos".

Neste sentido, Bourdieu (1983, p. 65) expõe:

A prática é, ao mesmo tempo, necessária e relativamente autônoma em relação à situação considerada em sua imediatidade pontual, porque ela é o produto da relação dialética entre uma situação e um habitus - en- 
tendido como um sistema de disposições duráveis e transponíveis que, integrando todas as experiências passadas, funciona em cada momento como uma matriz de percepções, apreciações e ações - e torna possível a realização de tarefas infinitamente diferenciadas, graças às transferências analógicas de esquemas, que permitem resolver os problemas da mesma forma, e às correções incessantes dos resultados obtidos, dialeticamente produzidas por esses resultados.

A prática não pode ser concebida como reação mecânica, diretamente determinada pelo habitus. Este, como esquema gerador de nossas ações, deve ser compreendido na perspectiva de uma disposição durável, mas não estática. Perrenoud et al (2001) utilizam o conceito de habitus como condutor das práticas dos professores e associa-o ao fazer cotidiano dos professores denominando-o de habitus profissional.

\section{HABITUS PROFISSIONAL}

O conceito de habitus profissional é utilizado por Perrenoud et al (2001) e se refere às rotinas construídas pelos professores ao longo de sua trajetória, utilizadas de forma inconsciente nos momentos em que considera oportuno.

Com o intuito de aprofundar o conhecimento a respeito da noção de habitus, recorremos a Bourdieu (1983) que diz ser o habitus uma “interiorização do exterior", modo sob o qual a sociedade está depositada nas pessoas, sob a forma de disposições duráveis, e que as guiam nas suas respostas às solicitações do seu meio social. Não é uma aptidão natural, é social. É durável, mas não é estático ou eterno.

Para Perrenoud et al (2001), o habitus profissional compõe-se de:

- rotinas (que o professor constrói ao longo dos seus anos de trabalho);

- momento oportuno (a utilização de saberes e representações explícitas capazes de dirigir uma ação);

- ação racional (utilização de certos conhecimentos, aliados ao raciocínio rápido, em extrema urgência) ${ }^{1}$

- improvisação regrada (parte imprevista na ação planejada, o agir na urgência).

O habitus traduz a nossa capacidade de operar, de forma prática, em uma rotina econômica. ${ }^{2}$ A partir disto, observamos que na prática pe- 
dagógica dos professores existem dois momentos distintos: aqueles em que há a utilização de saberes formais, de conteúdos; e, outros, nos quais há o envolvimento do habitus profissional (PERRENOUd et al, 2001).

Este habitus profissional, por não ser reflexivo, por estar baseado na repetição, nas rotinas e por consolidar algumas regularidades no cotidiano escolar, contribui para o desenvolvimento de um currículo oculto nas aulas e nas escolas.

A partir de observações participantes ${ }^{3}$ foi possível perceber a utilização de rotinas pelos professores e uma tendência ao agir na urgência. A utilização de rotinas fica explicitada em certas atitudes dos professores que se repetem, apesar dos diferentes contextos de trabalho (diferentes escolas) e das diferentes faixas etárias com que trabalha. Há uma tendência dos professores a agir na urgência por se depararem, cotidianamente, com situações não-previstas, como lecionar para duas turmas ao mesmo tempo, ou resolver conflitos entre alunos. ${ }^{4}$ Estes aspectos constituem o habitus profissional dos professores de educação física e tendem a produzir um currículo oculto escolar.

\section{CURRÍCULO OCULTO}

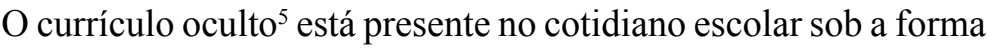
de aprendizagens não planejadas. Ele é resultado das relações interpessoais desenvolvidas na escola, da hierarquização entre administradores, direção, professores e alunos e da forma como os alunos são levados a se relacionarem com o conhecimento.

No cotidiano escolar, os alunos desenvolvem saberes que não constam nos planejamentos. Alguns, inclusive, não são desejados pelo professor e são aprendidos através das rotinas. A escola produz tipos particulares de conhecimentos em concordância com as relações sociais de produção capitalista, entre os quais a obediência, o trabalho alienado com avaliação externa e outros.

Para Bowles e Gintis (1981), existe o princípio da correspondência entre as relações escolares e as sociais. Os autores colocam que a hierarquização escolar e as relações sociais desenvolvidas no interior da escola correspondem às relações sociais de trabalho na sociedade capitalista. Sendo assim, a escola teria como função a reprodução da força de trabalho por meio de suas relações sociais. Os autores não ci- 
tam a expressão currículo oculto, mas consideram existir aprendizagens importantes não figuradas nos planejamentos.

Numa abordagem diferenciada, Silva (1992) considera que o tipo de relação estabelecido entre aluno e conhecimento é que produz um currículo oculto. Em seu estudo, conclui que, sob a aparência de uma escolarização de mesmo formato (séries, ano, horário), os alunos experimentam tipos bastante diversos de escolarização. Nas escolas que atendem a crianças de classes baixa e média, o conhecimento é aprendido numa relação de subordinação, ao passo que na escola de alunos de classes média e alta a aprendizagem contempla os princípios que estão por trás da produção do conhecimento.

Para Perrenoud (1996) existem três currículos que concorrem no cotidiano escolar:

- o currículo formal: que compreende uma cultura digna de se transmitir;

- o currículo real: que é o currículo desenvolvido pelo professor na sala de aula, é resultado do planejamento do professor com as interferências dos alunos, é o que realmente acontece nas aulas;

- o currículo oculto: onde figuram as aprendizagens regulares produzidas pela escola e que não constam nos planejamentos. Não se trata de adaptar os indivíduos à vida em sociedade, mas reforça nos alunos alguns valores/atitudes como a disciplina, o respeito, a necessidade do esforço pessoal.

Foi por meio de análises ao processo de escolarização e de técnicas de pesquisa que Apple (1989, p. 36, grifo do autor) considerou existirem elementos básicos do processo de escolarização que deveriam ser examinados: "as interações cotidianas e as regularidades do currículo oculto que tacitamente ensinavam normas e valores importantes; o corpus formal de conhecimento escolar - isto é, o próprio currículo oculto" e as perspectivas fundamentais que os educadores utilizam para planejar, organizar e avaliar as ações cotidianas da escola. Apple (apud SiLva, 2003) divide o currículo em aspectos estruturais e aspectos relacionais. Os estruturais se referem à organização escolar e ao conteúdo, enquanto os relacionais referem-se às relações interpessoais na escola e na sala de aula.

Para Apple (1989), no entanto, toda situação real (de trabalho ou escolar) apresenta elementos de contradição e de resistência com potencial transformador. $\mathrm{O}$ autor concebe, desta forma, o sistema de 
ensino e o currículo como fatores que podem estar a serviço da transformação das relações sociais desiguais na sociedade capitalista. ${ }^{6}$

Para Torres Santomé (1994), a discussão a respeito do currículo oculto nos faz perceber o significado de práticas e rotinas que, até pouco tempo, passavam despercebidas. São destrezas desenvolvidas nos alunos para que aprendam e interiorizem formas acríticas e irreflexivas de viver no atual modelo de sociedade.

Segundo o autor, o desenvolvimento do currículo oculto funciona de maneira implícita através dos conteúdos culturais, das rotinas, interações e tarefas escolares; não é fruto de um planejamento do coletivo docente. Torres Santomé (1994) assinala que este currículo é responsável pela reprodução das principais dimensões e peculiaridades da esfera econômica da sociedade.

Podemos observar que existem divergências entre os autores a respeito de quais fatores produzem o currículo oculto nas escolas. Estes fatores variam desde as relações interpessoais até a relação que se estabelece entre alunos e conhecimento. Em contrapartida, é possível notar que o currículo oculto é resultado da prática pedagógica dos professores, seja por meio das relações pessoais ou do trato com o conhecimento.

Por meio da observação de aulas de educação física foi possível perceber a produção de um currículo oculto baseado nos conteúdos desenvolvidos nas aulas, com predominância dos esportes, e na reduzida participação das meninas, ${ }^{7}$ sobretudo nos momentos coletivos. Outro fator importante é o número excessivo de alunos por professor; esta relação faz o professor produzir rotinas de trabalho e trabalhar de forma hierárquica, a fim de manter a turma organizada/ordenada, ou, como considera Woods (1987), os professores são obrigados a criar estratégias de sobrevivência. ${ }^{8}$

Com o objetivo de encaminhar a questão central deste trabalho, passamos a analisar os aspectos da prática pedagógica que aproximam habitus profissional e currículo oculto.

\section{RELAÇÕES ENTRE O HABITUS PROFISSIONAL E O CURRÍCULO OCULTO}

Buscando, inicialmente, esclarecer: habitus profissional e currículo oculto são construções teóricas utilizadas neste trabalho com o 
intuito de analisar e compreender a prática pedagógica dos professores. Sendo assim, ao desenvolver os dois conceitos, o presente texto possibilita que façamos algumas aproximações. Podemos citar como fatores que aproximam o habitus profissional e o currículo oculto as regularidades, a improvisação, as rotinas cotidianas utilizadas pelos professores, os valores, a hierarquização das relações no interior das escolas e a concepção de conhecimento presente na escola.

A improvisação e as regularidades, no sentido atribuído por Perrenoud et al (2001), são procedimentos utilizados pelo professor cotidianamente, responsáveis pelas aprendizagens tácitas dos alunos, que não figuram nos planejamentos e funcionam como currículo oculto, reproduzindo aspectos essenciais da sociedade capitalista.

Para Jacson (apud Torres SANTOMÉ, 1994), as práticas e as rotinas escolares possibilitam à escola desempenhar seu papel de forma não explícita, sendo o que o autor denomina de currículo oculto. Podemos constatar que, novamente, estes conceitos operam em unidade, favorecendo a reprodução das relações sociais existentes.

Segundo Torres Santomé (1994), a forma de organização escolar e os mobiliários também participam da rotina e da monotonia escolar, desenvolvendo aspectos relativos à subordinação e à obediência nos alunos. Silva (1992) explica o currículo oculto como resultado de uma trama complexa que envolve os rituais e as práticas escolares, as relações hierárquicas desenvolvidas na escola e as características físicas do ambiente escolar. As aprendizagens educacionais resultantes do currículo oculto são a docilidade, a obediência, a competição e as normas e atitudes para funcionar adequadamente numa sociedade injusta e desigual.

Por meio desta breve revisão teórica, constatamos que vários aspectos da prática pedagógica dos professores e do seu habitus profissional (as regularidades e as rotinas, a seleção e o trato dos conteúdos, as práticas e as relações interpessoais) funcionam como produtores de um currículo oculto.

\section{HABITUS PROFISSIONAL, TEMPO E INTENSIFICAÇÃO}

Observa-se, no entanto, que o trabalho dos professores sofre transformações ao longo do tempo. Há uma sobrecarga de trabalho crônica e persistente, uma redução do tempo de descanso e a dificuldade 
em manter-se atualizado profissionalmente. ${ }^{9}$ Para Hargreaves (1996), esses fatores constituem o fenômeno da intensificação e tornam o trabalho cada vez mais rotinizado, exigindo a necessidade de o professor dar respostas mais urgentes no cotidiano escolar. Desta forma, há uma tendência de os professores utilizarem programas prescritos e currículos impostos, para facilitar o controle de seu processo de trabalho.

A escassez de tempo para pensar e planejar a prática faz o professor produzir rotinas. Para Perrenoud et al (2001), o professor produz rotinas econômicas que derivam dos saberes práticos. Em outras palavras, práticas que deram certo são incorporadas ao habitus profissional dos professores. Na maioria das vezes, porém, são práticas não questionadas, ou seja, resolvem as situações de forma imediata. ${ }^{10}$

Em contrapartida, para que haja a conscientização do habitus profissional é necessário, entre outros aspectos, tempo para a reflexão, possibilitando trazer este habitus para a consciência. Sendo assim, a intensificação dificulta a superação do habitus profissional e favorece a utilização de rotinas e de materiais "pré-fabricados".

Ao trabalhar com a intensificação aliada ao habitus profissional torna-se possível montar uma cena que vai de encontro ao que sugere Perrenoud (2002, p. 173) em seu estudo sobre as possibilidades de formação de novo habitus profissional. Para o autor, é necessário fazer uma tomada de consciência do habitus, trazê-lo à tona, conhecê-lo: "A tomada de consciência muda o habitus porque o combate em tempo real e na situação".

Deste modo, a intensificação pode ser considerada fator que dificulta a formação de um novo habitus profissional, influenciando as possibilidades de mudança na prática pedagógica.

\section{HABITUS PROFISSIONAL E CULTURA DOCENTE}

A revisão bibliográfica realizada até o momento mostrou-nos que a linha que separa o habitus profissional da cultura docente é muito tênue. Afirmamos isto porque reconhecemos que a experiência, a prática, o conhecimento, a formação e as crenças, que constituem a cultura docente (Molina Neto, 1997), se aproximam dos fatores constituintes do habitus profissional.

Partindo de outro ponto de vista, Tardif et al (1991) problematiza o saber docente, procurando identificar e definir quais os saberes que intervêm 
na prática pedagógica dos professores. Nesta perspectiva, conclui que os professores se utilizam, em grande medida, dos saberes da experiência, ou seja, são saberes específicos desenvolvidos pelos professores, que se fundam nos saberes cotidianos e no conhecimento do meio. São saberes práticos e "incorporam-se à vivência individual e coletiva sob a forma de habitus e de habilidades, de saber fazer e de saber ser" (TARDIF, 1991, p. 220). Segundo o autor, os saberes da experiência formam um conjunto de representações a partir das quais os professores interpretam, compreendem e orientam sua profissão e sua prática, e constituem a cultura docente em ação. Hargreaves (1996, p. 36) considera

a cultura docente como uma construção histórica e coletiva que implica valores, crenças, hábitos e formas de fazer que cada coletivo de professores e professoras desenvolvem para enfrentar as demandas e pressões similares durante muitos anos. [Ainda chama a atenção] para a influência do contexto na configuração da cultura docente de diferentes coletivos de professores.

Para Silva (1992) existe uma pedagogia oculta nas escolas, resultante da falta de coordenação das atividades pedagógicas. Os professores tendem a utilizar como referência suas ações pedagógicas e sua visão idiossincrática de educação:

Apesar das diferenças individuais entre as professoras, são essas respostas que, em última instância, formam uma cultura docente específica, no sentido de um repertório de respostas comuns a problemas comuns. É essa cultura que, em cada escola, molda a pedagogia invisível específica (Silva, 1992, p. 125).

Nesta perspectiva, a cultura docente aproxima-se, em seus fatores constituintes e em suas conseqüências, ao que concebemos como o habitus profissional dos professores. É uma cultura baseada em juízos idiossincráticos, que se forma a partir dos conhecimentos práticos dos docentes e que promove aprendizagens não planejadas e não desejadas.

\section{CONSIDERAÇÕES TRANSITÓRIAS}

Consideramos que o conceito de habitus profissional se apresenta como importante instrumento de análise da prática pedagógica 
dos professores. No entanto, relacioná-lo à cultura docente e aos saberes experienciais utilizados pelos professores torna a abordagem mais complexa e possibilita melhor compreensão do que vem a ser currículo oculto resultante da prática pedagógica dos professores.

A análise da prática pedagógica dos professores não deve centrar-se apenas em um aspecto, como as relações interpessoais, o conteúdo ou, ainda, a produção das práticas pedagógicas a partir da cultura docente, mas deve utilizar-se de todos esses pontos de vista a fim de possibilitar a compreensão holística do fenômeno, com vistas à sua transformação.

Entretanto, é importante ressaltar a existência de fatores que contribuem para a perpetuação deste habitus profissional, como o fenômeno da intensificação, apontado por Hargreaves (1996), e outros que contribuem para a sua superação, a exemplo da produção do conhecimento no interior da escola, como aponta Silva (1992).

\title{
Professional habitus, hidden syllabus and teacher culture: perspectives in the analysis of pedagogical practices of physical education teachers
}

\begin{abstract}
This paper intends to articulate the concepts of professional habitus, hidden syllabus, and teacher culture as instruments for the analysis of pedagogical practices among physical education teachers. By conceiving pedagogical practice as a product of a context and of a professional habitus, this text discusses the production of a hidden syllabus that originates from teacher practices, considering that such a hidden syllabus can be the result of interpersonal relationships, school regulations and of the contents of a school subject or syllabus component. This paper also shows how the phenomenon of intensification reinforces teacher routines and hinders reflection derived from practice.
\end{abstract}

KEYWORDS: pedagogical practice - professional habitus - hidden syllabus

Habitus profesional, currículum oculto y cultura docente: perspectivas para el análisis de la práctica pedagógica de los professores de educación física

\section{RESUMEN}

El presente ensayo pretende articular conceptos de habitus profesional, currículo oculto y cultura docente como instrumentos de análisis de las prácticas pedagógicas de los profesores de educación física. Al concebir la práctica pedagógica como resultado de un contexto y de un habitus profesional, el texto discute la producción de un currículo oculto a partir de la práctica docente, considerando que el currículo oculto puede ser fruto de las relaciones interpersonales, de las normas escolares y de los contenidos de 
una asignatura/componente curricular. Incluso, el ensayo muestra como el fenómeno de la intensificación refuerza las rutinas de los profesores y dificulta la reflexión a partir de la práctica.

PALABRAS-CLAVE: práctica pedagógica - habitus profesional - currículo oculto

\section{NOTAS}

1 Esta ação racional não é estranha ao habitus.

2 Perrenoud et al (2001) concebe a rotina econômica como derivada dos saberes que os professores vão incorporando à prática, é a utilização de práticas que deram certo.

3 As observações participantes fazem parte do trabalho de campo que estamos realizando desde outubro de 2005, em uma escola municipal de Porto Alegre e que deve se estender até outubro de 2006.

4 Estas situações foram observadas durante o trabalho de campo e também foram relatadas em trabalhos recentes: Bossle (2003) e Pereira (2004).

5 O currículo oculto pode ser estudado de outros pontos de vista, como por exemplo o currículo oculto dos livros didáticos (Apple, 1989).

6 Neste aspecto, Silva (1992) coloca que a escola é local de reprodução e de produção. Produção de novos conhecimentos, de novas práticas, de superação.

7 Em trabalho de campo, observamos que grande parte dos estudantes que não participam dos momentos coletivos da aula são meninas. Assim como Apple (1989) trata do currículo oculto das relações interpessoais, Silva (1992) coloca que o currículo oculto pode ser produzido pelo trato com o conhecimento ou pela seleção do conhecimento. Consideramos que nas aulas de educação física são privilegiados os desportos como futebol e voleibol em detrimento de modalidades como as danças, ginástica artística, dentre outras atividades que poderiam interessar e incluir as meninas.

8 Woods (1987, p. 31) refere-se às estratégias de sobrevivência como "estrategias que permiten ante todo al maestro sobrevivir en su plaza, pero que no necesariamente facilitan la enseñanza".

9 Em relação a sobrecarga de trabalho podemos citar o aumento do número de dias letivos e de formação profissional. Também há o forte enfrentamento dos professores com as questões ligadas à desigualdade social e que se configuram num desafio cotidiano: crianças 
desestimuladas, choque cultural, fome, problemas básicos de saúde, entre outros. Gostaríamos de salientar que nosso objetivo não é discutir estes fatores, apenas estamos colocando-os como aspectos que, em nosso ponto de vista, interferem no trabalho dos professores.

${ }^{10}$ Neste aspecto, Silva (1992) coloca que predominam as visões idiossincráticas em educação, que os professores organizam seu trabalho a partir da expectativa que têm a respeito do futuro de seus alunos.

\section{REFERÊNCIAS}

APPLE, M. W. Repensando ideologia e currículo. In: MOREIRA, A. F.; SILVA, T. T. (Orgs.). Currículo, cultura e sociedade. São Paulo: Cortez, 1994. p. 39-58.

—. Educação e Poder. Porto Alegre: Artes Médicas, 1989.

BOSSLE, F. Planejamento de ensino dos professores de Educação Fisica do $2^{\circ}$ e $3^{\circ}$ ciclos da Rede Municipal de Ensino de Porto Alegre: um estudo do tipo etnográfico em quatro escolas desta rede de ensino. 2003. 271 f. Dissertação (Mestrado em Ciências do Movimento Humano) - Escola de Educação Física, Universidade Federal do Rio Grande do Sul, Porto Alegre, 2003.

BOURDIEU, P. Esboço de uma teoria da prática. In: ORTIZ, R. (Org.). Pierre Bourdieu. São Paulo: Ática, 1983. p. 46-81.

. Pierre Bourdieu. Entrevista concedida a Maria Andréa Loyola. Rio de Janeiro: UERJ, 2002.

BOWLES, S.; GINTIS, H. La instrucción escolar en la América capitalista. Madrid: Siglo Veintiuno, 1981.

HARGREAVES, A. Profesorado, cultura y postmodernidad: cambian los tiempos, cambia el profesorado. Madrid: Morata, 1996.

MOLINA NETO, V. A cultura do professorado de Educação Física nas escolas públicas de Porto Alegre. Movimento, Porto Alegre, ano 4, p. 31-46, 1997/2.

PEREIRA, R. R. A interdisciplinaridade na ação pedagógica do professor de educação física da Rede Municipal de Ensino de Porto Alegre. 
2004. 247 f. Dissertação (Mestrado em Ciências do Movimento Humano) - Escola de Educação Física, Universidade Federal do Rio Grande do Sul, Porto Alegre, 2004.

PERRENOUD, P. La construcción del êxito y del fracaso escolar. Madrid: Morata, 1996.

- A prática reflexiva no oficio de professor: profissionalização e razão pedagógica. Porto Alegre: Artmed, 2002.

PERRENOUD, P. et al. (Orgs.). Formando professores profissionais: quais estratégias? quais competências? Porto Alegre: Artmed, 2001.

SILVA, T. T. O que produz e o que reproduz em educação. Porto Alegre: Artmed, 1992.

. Documentos de identidade: uma introdução às teorias do currículo. Porto Alegre: Artmed, 2003.

TARDIF, M. Os professores face ao saber: esboço de uma problemática do saber docente. Teoria e educação, Porto Alegre, n. 4, p. 215-233, 1991.

TORRES SANTOMÉ, J. El curriculum oculto. 4. ed. Madrid: Morata, 1994.

WOODS, P. La escuela por dentro: la etnografía en la investigación educativa. (Temas de Educacion). Paidós: MEC, 1987.

Recebido: 31 de março de 2006 Aprovado: 10 de abril de 2006

Endereço para correspondência: Rua das Pitangueiras, 88, Cond. Cantegril II, Viamão Rio Grande do Sul CEP 94440-000 E-mails: $\begin{array}{r}\text { msanchotene@yahoo.com.br } \\ \text { vicente.neto@ufrgs.br }\end{array}$ 